\title{
Impaired baroreflex control of vascular resistance and heart rate in acute myocardial infarction
}

\author{
TSUTOMU IMAIZUMI, AKIRA TAKESHITA, NAOKI MAKINO, TOSHIAKI ASHIHARA, \\ KUNIHIKO YAMAMOTO, MOTOOMI NAKAMURA \\ From the Research Institute of Angiocardiology and the Cardiovascular Clinic, Faculty of Medicine, Kyushu \\ University, Fukuoka, fapan
}

SUMMARY The baroreflex control of vascular resistance and heart rate was studied in 11 patients to determine whether it is impaired in patients with acute myocardial infarction. Reflex forearm vasoconstriction in response to lower body negative pressure at $40 \mathrm{~mm} \mathrm{Hg}$ was less in the early convalescent phase (mean seven days) than in the late convalescent phase (mean 41 days). Pressor as well as vasoconstricting responses to the cold pressor test did not differ between the early and late convalescent phases. The slope of the regression line relating systolic blood pressure and the RR interval during a transient rise in blood pressure produced by intravenous phenylephrine was appreciably reduced in the early convalescent phase of myocardial infarction. These results suggest that baroreflex control of vascular resistance and heart rate is impaired in patients with acute myocardial infarction.

Studies in animals suggest that arterial baroreflex control of efferent sympathetic activity or vascular resistance is impaired during acute myocardial ischaemia or myocardial infarction. ${ }^{1-3}$ Arterial baroreflex control of heart rate is also inhibited in dogs during acute coronary occlusion. 4

Drug induced hypotension may not be associated with reflex tachycardia in patients with acute myocardial infarction, ${ }^{5-8}$ which suggests that there may be abnormal reflex control of heart rate. Kirby reported abnormal blood pressure responses to the Valsalva manoeuvre in patients with acute myocardial infarction.9 Baroreflex control of vascular resistance and heart rate had not, however, been examined systematically in patients with acute myocardial infarction. Responses to the Valsalva manoeuvre may be influenced by several factors, and thus the mechanisms of abnormal responses to this manoevre are difficult to determine. ${ }^{10}$

In this study we examined (a) reflex forearm vasoconstriction in response to lower body negative pressure, (b) the arterial baroreflex slope relating systolic

Requests for reprints to Dr Akira Takeshita,, Research Institute of Angiocardiology and Cardiovascular Clinic, Faculty of Medicine, Kyushu University, 3-1-1 Maidashi, Higashi-ku, Fukuoka 812, Japan.

Accepted for publication 5 June 1984 blood pressure and the $\mathbf{R} \mathbf{R}$ interval during a transient rise in blood pressure produced by intravenous phenylephrine, and $(c)$ blood pressure and forearm vascular responses to the cold pressor test in the early and late convalescent phases of myocardial infarction.

\section{Patients and methods}

Nine men and two women with acute myocardial infarction were studied. Their ages ranged from 43 to 66 (mean 54 (3)) years. The diagnosis of acute myocardial infarction was based on the development of new $Q$ waves and serial enzyme changes. Seven patients had inferior and four anterior myocardial infarctions. The clinical course was uneventful with no complications such as heart failure, hypotension, or serious arrhythmias. No vasoactive drugs were given to the patients. The study protocol was explained and consent obtained from all patients.

MEASUREMENT OF FOREARM BLOOD FLOW

The study was performed with the subjects supine and after a meal. The lower half of the subject's body below the iliac crest was enclosed in a sealed box connected to a vacuum. Forearm blood flow was measured with a mercury in silastic strain gauge plethysmograph using a venous occlusion technique as previously described. ${ }^{11}$ The strain gauge was 
placed approximately $5 \mathrm{~cm}$ below the antecubital crease. The pressure in the venous occlusion or congesting cuff was $40 \mathrm{~mm} \mathrm{Hg}$. Circulation to the hand was stopped by inflating a cuff around the wrist during determination of forearm blood flow. Blood pressure was measured in the other arm with a sphygmomanometer. Forearm vascular resistance was calculated by dividing the mean blood pressure $(\mathrm{mm} \mathrm{Hg})$ by the forearm blood flow $(\mathrm{ml} / \mathrm{min}$ per $100 \mathrm{ml}$ of forearm volume) and is expressed in units. Mean blood pressure was calculated by adding one third of the pulse pressure to the diastolic pressure.

To examine reflex forearm vasoconstriction the pressure inside the box was lowered by $40 \mathrm{~mm} \mathrm{Hg}$ below atmospheric pressure, which decreased venous return and caused reflex forearm vasoconstriction. Negative pressure was applied for one and a half minutes. The mean of five to eight flow measurements made at $15 \mathrm{~s}$ intervals was used for later analysis.

\section{DETERMINATION OF ARTERIAL BAROREFLEX CONTROL OF HEART RATE}

Arterial baroreflex control of heart rate was determined according to the previously described method. ${ }^{1213}$ In brief, patients were positioned supine, and an arterial cannula was inserted into the brachial artery for measuring arterial pressure. An electrocardiogram and arterial pressure were recorded on the same tracing at a paper speed of $10 \mathrm{~cm} / \mathrm{s}$. Phenylephrine ( $75 \mu \mathrm{g}$ bolus) was injected into an antecubital vein. Systolic blood pressure $(\mathrm{mm} \mathrm{Hg}$ ) and the preceding RR interval (ms) were plotted. The relation between systolic blood pressure and RR interval was examined by the method of least squares and the reflex sensitivity expressed as the slope of the regression line. ${ }^{12} 13$

\section{COLD PRESSOR TEST}

Ice was placed on the forehead for $45 \mathrm{~s}$ and forearm blood flow was measured continuously. Blood pressure was measured before and after the cold pressor test. Forearm vascular resistance after cold stimulus was compared with that before.

PROTOCOL

Studies in the early convalescent phase of myocardial infarction were performed between four and 13 days after acute myocardial infarction (mean 7 (1) days) and those in the late convalescent phase between 31 and 53 days after acute myocardial infarction (mean 41 (3) days).

The baroreflex control of heart rate during phenylephrine induced transient hypertension was measured in seven patients in the early convalescent phase and was repeated in four patients in the late convalescent phase of myocardial infarction. The studies of reflex vasocontriction with lower body negative pressure and the cold pressor test were performed in seven patients in the early and late convalescent phases.

\section{STATISTICAL ANALYSIS}

Student's paired $t$ test was used for statistical analysis for comparisons between the early and late convales-

Table Haemodynamic responses at rest and during lower body negative pressure and the cold pressor test in patients during the early and late convalescent phases after acute myocardial infarction

\begin{tabular}{|c|c|c|c|}
\hline & \multicolumn{3}{|c|}{ Convalescent phase } \\
\hline & Early & Late & $p$ value \\
\hline $\begin{array}{l}\text { Heart rate (beats/min) }(\mathrm{n}=11) \\
\text { Mean blood pressure }(\mathrm{mm} \mathrm{Hg})(\mathrm{n}=11) \\
\text { Forearm blood flow }(\mathrm{ml} / \mathrm{min} / 100 \mathrm{ml})(\mathrm{n}=7) \\
\text { Forearm vascular resistance (units) }(\mathrm{n}=7)\end{array}$ & $\begin{array}{l}\quad \text { Resting } \\
76(4) \\
92(2) \\
4 \cdot 5(0 \cdot 5) \\
22 \cdot 0(2 \cdot 1)\end{array}$ & $\begin{array}{l}68(3)^{\star} \\
93(2) \\
6 \cdot 8(0 \cdot 8)^{\star} \\
14 \cdot 8(1 \cdot 7)^{\star \star}\end{array}$ & $\begin{array}{l}<0.05 \\
<0.05 \\
<0.01\end{array}$ \\
\hline \multicolumn{4}{|c|}{ Lower body negative pressure $(n=7)$} \\
\hline $\begin{array}{l}\text { Change in: } \\
\text { Mean blood pressure (mm } \mathrm{Hg}) \\
\text { Forearm blood flow (ml/min } 100 \mathrm{ml}) \\
\text { Forearm vascular resistance (units) } \\
\% \text { change }\end{array}$ & $\begin{array}{l}+1(2 \cdot 0) \\
-1 \cdot 2(0 \cdot 4) \\
+11(3) \\
27(10)\end{array}$ & $\begin{array}{l}-1(1 \cdot 9) \\
-2 \cdot 9(0 \cdot 3) \\
+16(2) \\
107(18)\end{array}$ & $\begin{array}{l}<0.01 \\
<0.01\end{array}$ \\
\hline \multicolumn{4}{|c|}{ Cold pressor test $(n=7)$} \\
\hline $\begin{array}{l}\text { Mean blood pressure }(\mathrm{mm} \mathrm{Hg}) \\
\text { Forearm blood flow }(\mathrm{ml} / \mathrm{min} / 100 \mathrm{ml}) \\
\text { Forearm vascular resistance (units) } \\
\% \text { change }\end{array}$ & $\begin{array}{l}+10(1) \\
-0 \cdot 5(0 \cdot 3) \\
+7(2) \\
+31(10)\end{array}$ & $\begin{array}{l}+10(1) \\
+0 \cdot 2(0 \cdot 6) \\
+4(2) \\
+18(9)\end{array}$ & \\
\hline Baroreflex slope $(\mathrm{n}=4)(\mathrm{ms} / \mathrm{mm} \mathrm{Hg})$ & $0.7(0.1)$ & $6.1(0.4)$ & $<0.01$ \\
\hline
\end{tabular}




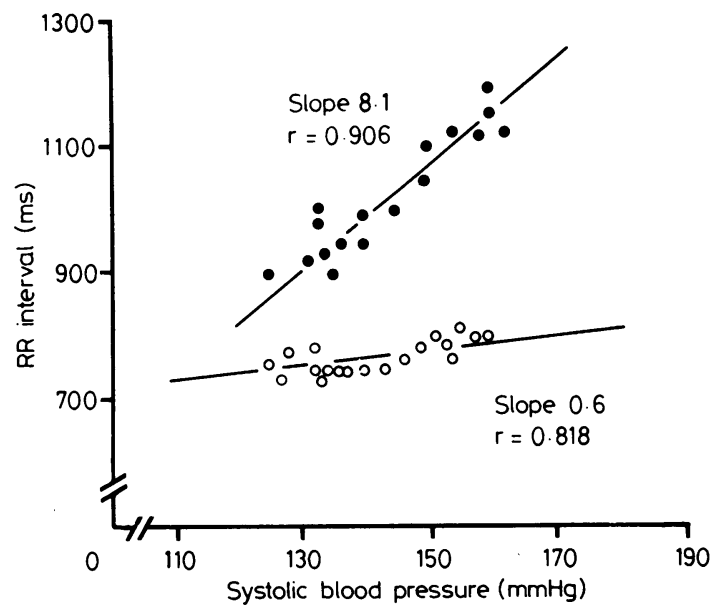

Figure Baroreflex slope in a patient with acute inferior myocardial infarction. (O) early convalescent phase; $(\Theta)$ late convalescent phase of myocardial infarction.

cent phases, and $\mathrm{p}<0.05$ was considered to be significant. Data are expressed as mean (SEM).

\section{Results}

The Table shows the haemodynamic responses in the early and late convalescent phases of myocardial infarction. At rest heart rate was slower, forearm blood flow greater, and forearm vascular resistance lower in the late convalescent phase than in the early convalescent phase. Mean blood pressure did not differ between the early and late convalescent phases. The decrease in forearm blood flow and the percentage increase in forearm vascular resistance in response to lower body negative pressure at $40 \mathrm{~mm}$ $\mathrm{Hg}$ were greater in the late convalescent phase than in the early convalescent phase (Table). The percentage increase in forearm vascular resistance was greater $(p<0.01)$ in the late convalescent phase than in the early convalescent phase. Responses to the cold pressor test did not, however, differ between the two phases.

The arterial baroreflex slope was appreciably depressed in the early convalescent phase of myocardial infarction in seven patients (mean $0.7(0.1) \mathrm{ms} /$ $\mathrm{mmHg}$ ), which suggests that arterial baroreflex control of heart rate is depressed in the early convalescent phase of myocardial infarction (Table). In four patients in whom studies were repeated in the late convalescent phase the slope of the regression line relating systolic blood pressuri and the $R R$ interval was steeper in the late convalescent phase than in the early convalescent phase (Table). The Figure shows the baroreflex slopes of one patient in the early and late convalescent phases of inferior myocardial infarc- tion. Prolongation of the $R R$ interval in responses to an increase in blood pressure was appreciably less in the early convalescent phase compared with that in the late convalescent phase of myocardial infarction.

\section{Discussion}

The results indicate that reflex forearm vasoconstriction during lower body negative pressure at $40 \mathrm{~mm}$ $\mathrm{Hg}$ was impaired in the early convalescent phase compared with that in the late convalescent phase of myocardial infarction. The arterial baroreflex slope assessed by relating the $R R$ interval to the preceding systolic blood pressure during phenylephrine induced transient hypertension was also reduced in the early convalescent phase. These findings suggest that reflex control of vascular resistance and heart rate is impaired during the early convalescent phase.

Impaired reflex control of vascular resistance and heart rate may result from non-specific mechanisms. Firstly, the arterial baroreflex slope may be influenced by baseline heart rate, the slope being reduced if baseline heart rate is increased. ${ }^{14} 15$ In our study baseline heart rate was higher in the early convalescent phase than in the late convalescent phase of myocardial infarction. Nevertheless, there was virtually no reflex slowing of the heart rate during the transient rise in blood pressure in the early convalescent phase (Table, Figure). Mild relative tachycardia is unlikely to explain such a pronounced reduction in reflex heart rate control since in a previous study the baroreflex slope was only slightly reduced with a similar heart rate. ${ }^{16}$

Other possible non-specific mechanisms for the decrease in reflex forearm vasoconstriction with lower body negative pressure might be the difference in baseline forearm vascular resistance or the level of reflex stimulus to the baroreceptors. Vascular responses to reflex sympathetic activation would be less if baseline vascular resistance is increased. ${ }^{17}$ In our study baseline forearm vascular resistance was greater in the early convalescent phase than in the late convalescent phase. Nevertheless, this mechanism is unlikely to explain the results since forearm vascular responses to the cold pressor test did not differ between the early and late convalescent phases. The level of reflex stimulus to the baroreceptors did not differ between the two phases. The mean blood pressure did not change with lower body negative pressure and nor did the decreases in systolic blood pressure differ between the early and late convalescent phases (average 8 (2) $\mathrm{mm} \mathrm{Hg} v 10$ (2) $\mathrm{mm} \mathrm{Hg}$ respectively). In three patients, the decreases in central venous pressure with lower body negative pressure were similar between the early and late convalescent phase of myocardial infarction (average $4.0(1.1) \mathrm{mm} \mathrm{Hg} v \mathbf{4 . 8}$ 
(1.0) $\mathrm{mm} \mathrm{Hg}$ respectively). Thus we consider that impaired reflex forearm vasoconstriction was unlikely to be due to these non-specific mechanisms.

The mechanisms of impaired reflex control of vascular resistance and heart rate in the early convalescent phase of myocardial infarction are not explained by these studies. Animal studies suggest that increased vagal afferents from cardiac receptors which are stimulated by acute myocardial ischaemia or myocardial infąrction may interfere with arterial baroreceptor responses. ${ }^{1-3}$ It is conceivable that similar mechanisms are involved in man.

Studies in dogs suggest that reflex inhibition of sympathetic activity during coronary occlusion is greater with myocardial ischaemia of the inferior wall than of the anterior wall of the left ventricle. ${ }^{18}$ Inferior myocardial infarction is often associated with sinus bradycardia. ${ }^{19}$ In this study, reflex forearm vasoconstriction with lower body negative pressure in the early convalescent phase of myocardial infarction tended to be less in inferior myocardial infarction (change in forearm vascular resistance 6.1 (2.4) units) than in anterior myocardial infarction (change in forearm vascular resistance $17 \cdot 1$ (4.7) units). This difference was not, however significant, probably owing to the small number of patients.

The results in this study may have important clinical implications. The presence of impaired reflex control of vascular resistance and heart rate should be considered when hypotensive drugs are given to patients with acute myocardial infarction. An orthostatic fall in blood pressure should be carefully looked for in these patients.

\section{References}

1 Toubes DB, Brody MJ. Inhibition of reflex vasoconstriction after experimental coronary embolization in the dog. Circ Res 1970; 26: 211-24.

2 Kezdi P, Kordenat RK, Misra SN. Reflex inhibitory effects of vagal afferents in experimental myocardial infarction. Am F Cardiol 1974; 33: 853-60.

3 Felder RB, Thames MD. Interaction between cardiac receptors and sinoaortic baroreceptors in the control of efferent cardiac sympathetic nerve activity during myocardial ischemia in dogs. Circ Res 1979; 45: 728-36.

4 Takeshita A, Matsuguchi H, Nakamura M. Effect of coronary occlusion on arterial baroreflex control of heart rate. Cardiovasc Res 1980; 14: 303-6.

5 Thomas M, Malmcrona R, Shillingford J. Circulatory changes associated with systemic hypotension in patients with acute myocardial infarction. Br Heart $\mathcal{F}$ 1966; 28: 108-17.

6 Smith WW, Wikler NS, Fox AC. Hemodynamic studies of patients with myocardial infarction. Circulation 1954; 9: 352-62.

7 Gunnar RM, Cruz A, Boswell J, Co BS, Pietras RJ, Tobin JR Jr. Myocardial infarction with shock: hemodynamic studies and results of therapy. Circulation 1966; 33: 753-62.

8 Gunnar RM, Loeb HS, Pietras RJ, Tobian JR. Ineffectiveness of isoproterenol in shock due to acute myocardial infarction. FAMA 1967; 202: 1124-8.

9 Kirby BJ. Circulatory reflexes in myocardial infarction. Br Heart f 1977; 39: 168-72.

10 Eckberg DL. Parasympathetic cardiovascular control in human disease: a critical review of methods and results. Am $\mathcal{F}$ Physiol 1980; 239: H581-93.

11 Takeshita A, Imaizumi T, Ashihara T, Yamamoto K, Hoka S, Nakamura M. Limited maximal vasodilator capacity of forearm resistance vessels in normotensive young men with a familial predisposition to hypertension. Circ Res 1982; 50: 671-7.

12 Smyth HS, Sleight P, Pickering GW. Reflex regulation of arterial pressure during sleep in man: a quantitative method of assessing baroreflex sensitivity. Circ Res 1969; 24: 109-21.

13 Takeshita A, Tanaka S, Kuroiwa A, Nakamura M. Reduced baroreceptor sensitivity in borderline hypertension. Circulation 1975; 51: 738-42.

14 Pickering TG, Gribbin B, Petersen ES, Cunningham DJC, Sleight P. Effects of autonomic blockade on the baroreflex in man at rest and during exercise. Circ Res 1972; 30: 177-85.

15 Eckberg DL, Abboud FM, Mark AL. Modulation of carotid baroreflex responsiveness in man: effects of posture and propranolol. F Appl Physiol 1976; 41: 383-7.

16 Takeshita A, Tanaka S, Nakamura M. Effects of propranolol on baroreflex sensitivity in borderline hypertension. Cardiovasc Res 1978; 12: 148-51.

17 Myers HA, Honig CR. Influence of initial resistance on magnitude of response to vasomotor stimuli. Am $\mathcal{F}$ Physiol 1969; 216: 1429-36.

18 Thames MD, Klopfenstein HS, Abboud FM, Mark AL, Walker JL. Preferential distribution of inhibitory cardiac receptors with vagal afferents to the inferoposterior wall of the left ventricle activated during coronary occlusion in the dog. Circ Res 1978; 43: 512-9.

19 Webb SW, Adgey AAJ, Pantridge JF. Autonomic disturbance at onset of acute myocardial infarction. $\mathrm{Br}$ Med f 1972; 3: 89-92. 